\title{
Intakes of milk and alternatives among on-reserve First Nations youth in northern and southern Ontario, Canada
}

\author{
Michelle Gates ${ }^{1, *}$, Rhona M Hanning ${ }^{1,2}$, Allison Gates ${ }^{1}$, lan D Martin ${ }^{3}$ and \\ Leonard JS Tsuji ${ }^{3}$ \\ 'School of Public Health and Health Systems, University of Waterloo, 200 University Ave. West, Waterloo, \\ Ontario N2L 3G1, Canada: ${ }^{2}$ Propel Centre for Population Health Impact, University of Waterloo, Waterloo, \\ Ontario, Canada: ${ }^{3}$ Department of Environment and Resource Studies, University of Waterloo, Waterloo, \\ Ontario, Canada
}

Submitted 19 July 2011: Final revision received 1 May 2012: Accepted 4 May 2012: First published online 4 July 2012

\begin{abstract}
Objective: To assess the adequacy of milk and alternatives, Ca and vitamin D intakes in First Nations (FN) youth in Ontario, Canada. Intakes were compared with the general population and dietary standards. Variation in intakes by community (proxy for remoteness) and BMI was examined.

Design: Data were collected by $24 \mathrm{~h}$ recall between November 2003 and June 2010. Intakes were analysed descriptively. Variation in intakes, by community and BMI category, was assessed using ANOVA.

Setting: Five remote FN communities of the Mushkegowuk Territory (northern Ontario, Canada) and two less-remote southern Ontario FN communities.

Subjects: Schoolchildren ( $n$ 457) in grades 6 to 12.

Results: Compared with Canada's Food Guide recommendations, $72 \cdot 6$ to $84 \cdot 7 \%$ had an inadequate intake of milk and alternatives depending on age and sex group; $86 \cdot 2 \%$ of individuals fell below the RDA for $\mathrm{Ca} ; 96 \cdot 4 \%$ fell below the RDA for vitamin D. Community variation in intakes was detected, although in all cases Fort Albany had higher intakes, even when it was the more northern (remote) community. A BMI $\times$ sex interaction was found for intake of milk and alternatives $(P=0 \cdot 041)$ : an inverse relationship between intake and BMI was seen in females; in males, those who were overweight had the highest intake, followed by normalweight and obese youth.

Conclusions: The nutritional inadequacies parallel the results of other Canadian studies of Aboriginal populations. Population health interventions to improve intakes are warranted. Moreover, community variation in intakes exists among FN youth in the present study (Fort Albany pairs only), but results were not as expected.
\end{abstract}

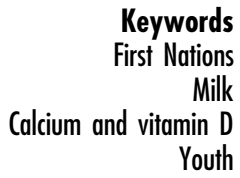

Keywords

Milk

Youth
The high prevalence rate of childhood overweight and obesity is of concern in Canada, with Aboriginal (includes First Nations, Inuit and Métis people in Canada) youth demonstrating higher rates than youth from other ethnic groups $^{(1,2)}$. This is a multifactorial problem; physical inactivity, food intake, genetic susceptibility, physical and social environments play a role ${ }^{(3)}$. Epidemiological studies have shown an inverse association between dietary Ca consumption and body weight ${ }^{(4,5)}$. Beyond the problem of obesity, adequate Ca and vitamin D intakes, for which milk and alternatives (a food group in Canada's Food Guide ${ }^{(6)}$ ) are the main dietary source, are of importance for Aboriginal populations because they are at increased risk of bone fracture ${ }^{(7-9)}$. 'Milk and alternatives' include milk-containing foods and $\mathrm{Ca}$ - and/or vitamin D-rich alternatives (e.g. canned, dry or fluid milk; cheese; yoghurt; fortified soya beverage; some fortified orange juices; some tofu). A recent study of Aboriginal children in northern Quebec, Canada found that more than $80 \%$ had intakes of milk and alternatives below national standards ${ }^{(10)}$. Further, a literature review investigating the food intake of Aboriginal people in Canada has revealed diets that are low in $\mathrm{Ca}$ and vitamin $\mathrm{D}$, among other nutrients ${ }^{(1)}$. Many barriers exist to healthy eating in remote First Nations (FN) communities, including a lack of variety and availability, and high food cost. Few data exist on the intakes of milk and alternatives, Ca and vitamin D among on-reserve FN youth, as Canadian national dietary surveys generally exclude on-reserve populations. Given the diversity of challenges faced by each FN community, research into the dietary status of individuals in various communities is of significance. 


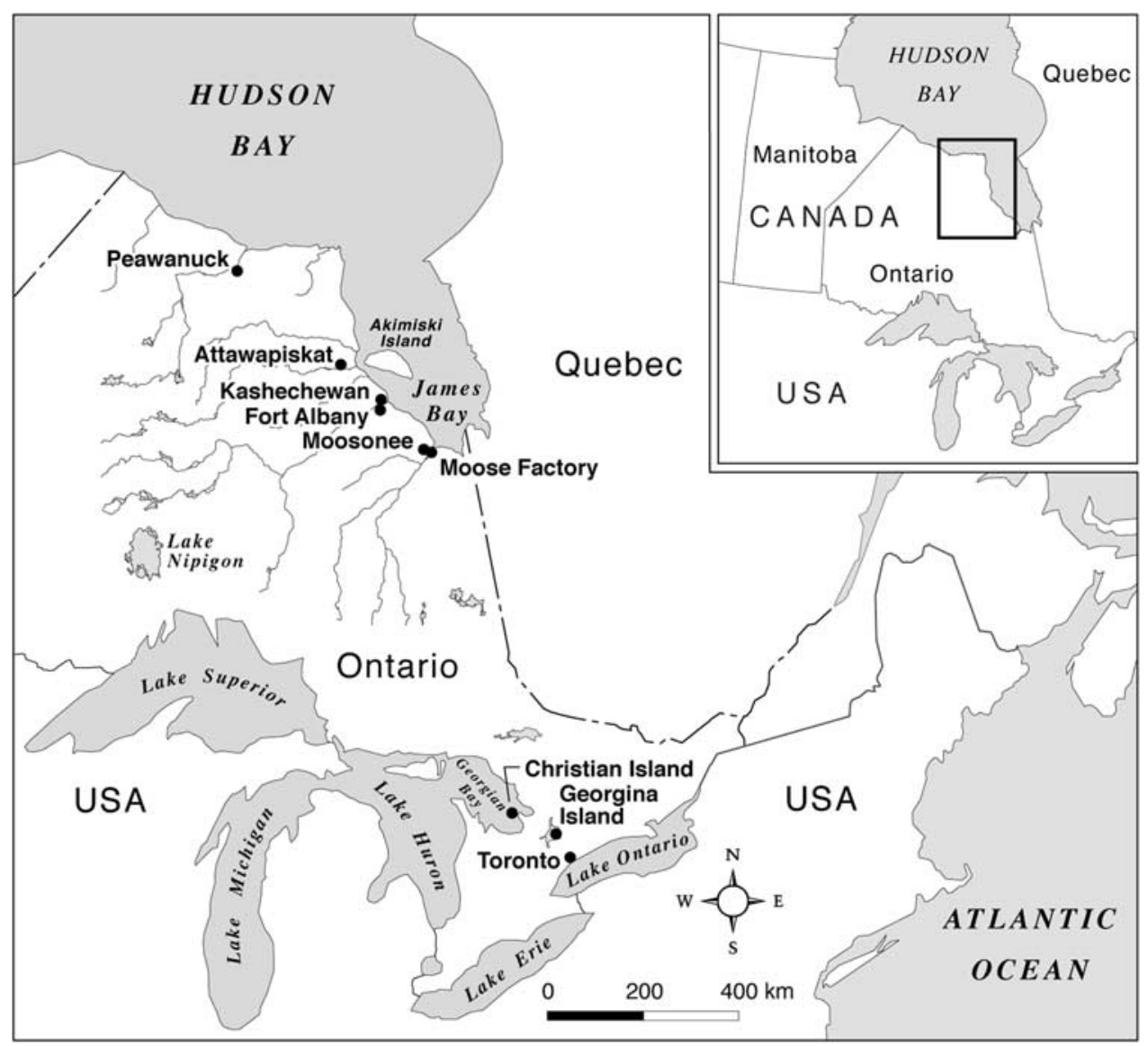

Fig. 1 Map of the Ontario First Nations communities included in the analysis

The objectives of the present paper were to investigate: (i) the adequacy of milk and alternatives, Ca and vitamin D intakes of youth living in remote (distant from major urban centres) FN communities of the Mushkegowuk Territory, northern Ontario, Canada and in less-remote southern Ontario FN communities as compared with dietary standards; (ii) the relationship of these intakes to categories of BMI (normal weight, overweight, obese); and (iii) the relationship of these intakes to categories of community (as a proxy measure of remoteness, affecting availability, quality and cost of consumables). In northern Ontario communities, the cost of foods has been reported to be typically at least double what is seen in southern Ontario ${ }^{(11)}$. It is expected that the increased cost of shipping goods further north, and the decreased availability and associated increased cost of food in community stores, will lead to lower intakes in more remote (northern) communities.

\section{Experimental methods}

\section{Sampling and data collection}

The Waterloo Web-based Eating Behaviour Questionnaire (WEB-Q) ${ }^{(12)}$, which was modified for use in each FN after feedback from community-based advisory groups and includes traditional FN foods, was used to collect dietary data in the school setting between November 2003 and June 2010. Assessments included all students in grades 6 to 12 who attended school on the day(s) of the survey. Schools in the geographically remote northern Ontario FN of the Mushkegowuk Territory (i.e. Moose Factory, Fort Albany, Kashechewan, Attawapiskat and Peawanuck) and in the southern Ontario FN of Christian Island and Georgina Island were included (Fig. 1). The most southern of the remote communities studied, Moose Factory, is approximately $315 \mathrm{~km}$ by air to Timmins (travel hub to the northern communities) and $850 \mathrm{~km}$ to Toronto, Ontario. The most northern study community, Peawanuck, is approximately $750 \mathrm{~km}$ by air to Timmins and more than $1300 \mathrm{~km}$ to Toronto. The northern Ontario communities are accessible only by air year round and by ice road in the winter. Most of these communities have only one grocery store. By contrast, the southern Ontario FN communities are less remote (but located on islands) and have greater access to grocery stores. Data collection times were scheduled to coincide with times (seasons) when most of the children would be in school; that is, scheduling had to account for socio-cultural factors, such as traditional harvesting activities. Nevertheless, there were some instances when planned collections were 
Table 1 Participation rates for the study by community and data collection date: First Nations communities, northern and southern Ontario, Canada

\begin{tabular}{|c|c|c|c|c|c|c|}
\hline \multirow[b]{2}{*}{ Community } & \multirow[b]{2}{*}{ Dates of WEB-Q* } & \multicolumn{5}{|c|}{ Participation rate } \\
\hline & & $\begin{array}{l}\text { Proportion of students in attendance } \\
\text { who completed the WEB-Q }\end{array}$ & $\%$ & $\begin{array}{l}\text { Proportion of students } \\
\text { who completed the }\end{array}$ & $\begin{array}{l}\text { ts enrolled } \\
\text { WEB-Q }\end{array}$ & $\%$ \\
\hline \multirow[t]{2}{*}{ Attawapiskat } & 22 Feb 2006 & 62 of 62 & 100 & \multicolumn{3}{|c|}{ Unavailable } \\
\hline & 4 Mar 2010 & 69 of 69 & 100 & 69 of 96 & & 72 \\
\hline Christian Island & 19-20 Oct 2004 & 44 of 44 & 100 & 44 of 50 & & 88 \\
\hline \multirow{3}{*}{ Fort Albany } & $10-12$ Nov 2004 & 66 of 66 & 100 & 66 of 77 & & 86 \\
\hline & 12-13 Dec 2007 & 50 of 50 & 100 & 50 of 60 & & 83 \\
\hline & 3-4 Jun 2009 & 30 of 30 & 100 & \multicolumn{3}{|c|}{ Unavailable } \\
\hline Georgina Island & 9 Dec 2003 & 12 of 12 & 100 & 12 of 14 & & 86 \\
\hline Kashechewan & 26-28 May 2009 & 43 of 43 & 100 & \multicolumn{3}{|c|}{ Unavailable } \\
\hline Moose Factory & $20-23$ Feb 2007 & 81 of 81 & 100 & 81 of 84 & & 96 \\
\hline \multirow[t]{2}{*}{ Peawanuck } & 7-8 Dec 2005 & 11 of 11 & 100 & 11 of 13 & & 85 \\
\hline & $1-2$ Jun 2010 & 13 of 13 & 100 & 13 of 15 & & 87 \\
\hline
\end{tabular}

*Web-Based Eating Behaviour Questionnaire.

cancelled due to unforeseen circumstances (e.g. power outages, flu outbreaks, inclement weather) and rescheduled for the next available time. Participants completed the WEB-Q on school computers during class time. To optimize participation rates (Table 1), data collection often occurred over two or more days, so absent individuals could participate on subsequent days.

The WEB-Q collects self-reported dietary information with a $24 \mathrm{~h}$ recall using a multiple-pass methodology ${ }^{(12)}$. A recent comprehensive review of electronic dietary assessment instruments supports the feasibility and benefits of this approach ${ }^{(13)}$. Dietary data collected represent weekday (Monday to Thursday, as the WEB-Q was completed only on Tuesday to Friday) intakes of nutrients from food alone; use of vitamin and mineral supplements was rare. Demographic information was also collected via the WEB-Q. Research assistants were trained to measure participants' height using predefined guidelines. Participants weighed themselves using an analogue scale (light clothing, no shoes), with help from a research assistant. Participants then self-reported their height and weight in the WEB-Q. BMI was computed electronically, and individuals were assigned to normal weight (includes underweight), overweight or obese categories using the International Obesity Taskforce BMI cut-offs for children and youth ${ }^{(14)}$. Using these cut-offs, an overweight youth would have a BMI that would be considered equivalent to an adult with $\mathrm{BMI} \geq 25 \cdot 0 \mathrm{~kg} / \mathrm{m}^{2}$, while an obese youth would have a BMI that would be considered equivalent to an adult with $\mathrm{BMI} \geq 30 \cdot 0 \mathrm{~kg} / \mathrm{m}^{2(14)}$. Nutrient calculations were performed electronically using the Canadian Nutrient File, version 2001 or 2007 depending on the year of the data collection (ESHA Food Processor, Salem, OR, USA) ${ }^{(15)}$. The 2007 version is an update of the 2001 version, the database being expanded to include foods newer to the market.

The study was conducted according to the guidelines laid down in the Declaration of Helsinki and all procedures using human subjects were approved by the University of Waterloo, Office of Research Ethics. Informed passive consent, which is culturally appropriate for the communities studied, was obtained by sending letters home to parents explaining the nature of the study. Individuals could refuse to participate at any time, without consequence. Informed consent was obtained from participating students as part of the WEB-Q.

\section{Statistical analyses}

Mean intakes of milk and alternatives, Ca and vitamin D were compared with national standards, including Dietary Reference Intakes (DRI) and Eating Well with Canada's Food Guide for First Nations, Inuit, and Métis servings ${ }^{(6,16)}$, by age category and sex. Comparison with means from the 2004 Canadian Community Health Survey Cycle 2.2: Nutrition was used to contrast intakes from the study group with the general population ${ }^{(17)}$, by age category and sex. Data sets included in the nutrient analysis were Christian Island (Autumn 2004), Georgina Island (Winter 2003), Moose Factory (Winter 2007), Fort Albany (Autumn 2004, Winter 2007), Kashechewan (Spring 2009), Attawapiskat (Winter 2006 and 2010) and Peawanuck (Winter 2005, Spring 2010). Variation in intakes of milk and alternatives, Ca and vitamin D by BMI category was assessed by ANOVA, using the previously stated data sets. Community variation (impact of remoteness) in intakes was assessed using ANOVA to compare community pairs; dietary data were collected during the same season and year to control for those factors known to affect intakes (K Skinner, RM Hanning, ID Martin et al., unpublished results). The community pairs assessed were Attawapiskat and Peawanuck (Winter 2005-2006), Christian Island and Fort Albany (Autumn 2004), Moose Factory and Fort Albany (Winter 2007), and Fort Albany and Kashechewan (Spring 2009). In each of the previously stated pairs, the latter community is more northern (remote). In the community and BMI analyses, all dietary variables were adjusted for energy intake using the energy density method (per $4184 \mathrm{~kJ}$ $(1000 \mathrm{kcal}))^{(18)}$. This helped to account for differences 
in age and sex distribution between communities, since older youths and males tend to consume more energy. Intakes were also controlled for season and year, for reasons discussed previously. For all analyses, variables were transformed as necessary to ensure homogeneity of variances. Statistical analyses were performed using the SPSS statistical software package version $17 \cdot 0$ (2008; SPSS Inc.). $P=0.05$ was adopted as the level of significance.

\section{Results}

\section{Participant characteristics}

All students attending school during the dates of data collection participated; that is, there was a $100 \%$ participation rate of students in attendance. Participation rates for each data collection, as calculated for all youth enrolled in the targeted grades for a particular community, are shown in Table 1. Participants' demographic characteristics are displayed in Table 2. A total of 456 participants completed the WEB-Q. Individuals who failed to report $24 \mathrm{~h}$ recall data $(n 8)$, who did not include their age $(n 4)$ or who were older than 18 years $(n 1)$ were excluded. Thus, a total of 443 individuals were included in the dietary standard analysis. The Fort Albany Spring 2009 data set ( $n$ 30) was included only in remoteness pairing analysis (as participants overlapped with the Fort Albany Winter 2007 data set).

\section{Comparison of intakes with dietary standards and Canadian population intakes}

Tables 3 and 4 summarize the mean and median intakes of milk and alternatives, $\mathrm{Ca}$ and vitamin $\mathrm{D}$ by age and sex category, in comparison with dietary standards and with intakes in the general population. Mean intake of milk and alternatives was below the minimum recommendations of Canada's Food Guide in all sex-age groups. More than $10 \%$ of the population consumed no milk and alternatives on the day of the study. All subgroups appeared to have a mean intake of milk and alternatives that fell below the mean intake seen in the general population. Among those with inadequate milk and alternatives consumption, dietary Ca and vitamin D intakes were significantly lower $(P<0 \cdot 001$, data not shown) as compared with those achieving adequacy. Overall, $86 \cdot 2 \%$ (range: from $75 \cdot 3 \%$ in males $14-18$ years to $98 \cdot 3 \%$ in females $14-18$ years) of individuals had an intake of Ca below the $\mathrm{RDA}^{(16)}$ and $96 \cdot 4 \%$ (range: from $90 \cdot 4 \%$ in males $14-18$ years to $98 \cdot 3 \%$ in females 14-18 years) of individuals had an intake of vitamin $D$ below the RDA.

\section{Association between milk and alternatives intake and BMI}

Of the 443 participants with complete dietary data, 107 were missing either height or weight data and were excluded because BMI could not be calculated. Height and weight data were not collected during the Fort

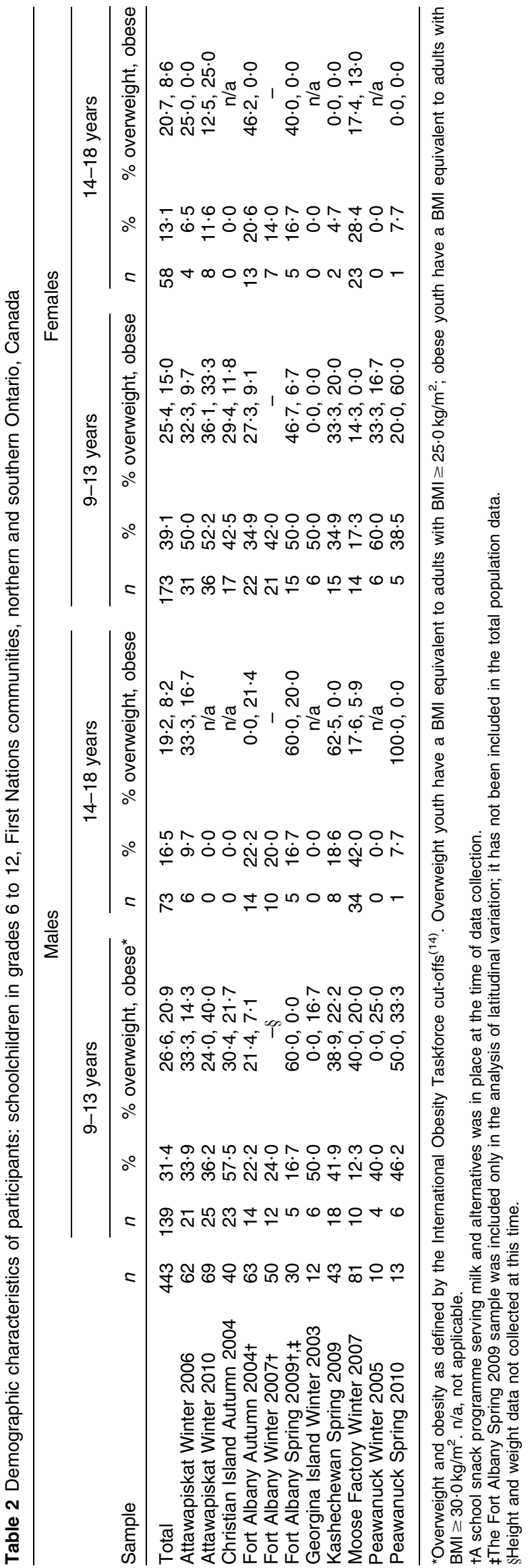


Table 3 Mean and median intakes of milk and alternatives (servings/d) in comparison to the general population and Canada's Food Guide (CFG) standards: schoolchildren in grades 6 to 12, First Nations communities, northern and southern Ontario, Canada

\begin{tabular}{|c|c|c|c|c|c|c|}
\hline \multirow[b]{2}{*}{ Age and sex } & \multirow[b]{2}{*}{$n$} & \multicolumn{3}{|c|}{ Intake } & \multirow[b]{2}{*}{ General population mean* } & \multirow[b]{2}{*}{$\%$ below CFG†,‡ } \\
\hline & & Mean & $\mathrm{SD}$ & Median & & \\
\hline Males 9-13 years & 139 & $1 \cdot 9$ & $1 \cdot 7$ & $1 \cdot 5$ & $2 \cdot 55$ & $79 \cdot 9$ \\
\hline Females 9-13 years & 173 & $1 \cdot 9$ & $2 \cdot 2$ & $1 \cdot 5$ & $2 \cdot 08$ & $83 \cdot 8$ \\
\hline Males $14-18$ years & 73 & $2 \cdot 5$ & $2 \cdot 1$ & $2 \cdot 0$ & $2 \cdot 64$ & $72 \cdot 6$ \\
\hline Females $14-18$ years & 58 & $1 \cdot 5$ & $1 \cdot 3$ & $1 \cdot 5$ & $1 \cdot 82$ & $84 \cdot 7$ \\
\hline
\end{tabular}

*Derived from means reported in the 2004 Canadian Community Health Survey Cycle 2·2: Nutrition ${ }^{(16)}$.

tEating Well with Canada's Food Guide for First Nations, Inuit, and Métis ${ }^{(6)}$.

$\ddagger$ The minimum number of servings (3) was used in all statistical analyses.

Table 4 Mean and median intakes of calcium and vitamin D in comparison to dietary standards: schoolchildren in grades 6 to 12 , First Nations communities, northern and southern Ontario, Canada

\begin{tabular}{|c|c|c|c|c|c|c|c|c|c|}
\hline \multirow[b]{3}{*}{ Age and sex } & \multirow[b]{3}{*}{$n$} & \multicolumn{4}{|c|}{$\mathrm{Ca}$} & \multicolumn{4}{|c|}{ Vitamin D } \\
\hline & & \multicolumn{3}{|c|}{ Intake (mg/d) } & \multirow[b]{2}{*}{$\%$ below RDA* } & \multicolumn{3}{|c|}{ Intake $(\mu \mathrm{g} / \mathrm{d})$} & \multirow[b]{2}{*}{$\%$ below RDAt } \\
\hline & & Mean & SD & Median & & Mean & SD & Median & \\
\hline Males 9-13 years & 139 & $775 \cdot 2$ & 573.6 & $673 \cdot 0$ & $86 \cdot 3$ & $3 \cdot 2$ & 3.5 & $2 \cdot 5$ & $98 \cdot 6$ \\
\hline Females $9-13$ years & 173 & $762 \cdot 7$ & $658 \cdot 6$ & $608 \cdot 9$ & $86 \cdot 7$ & $3 \cdot 6$ & 3.9 & $2 \cdot 7$ & $96 \cdot 5$ \\
\hline Males $14-18$ years & 73 & $1028 \cdot 1$ & $711 \cdot 8$ & $902 \cdot 7$ & $75 \cdot 3$ & $5 \cdot 3$ & $5 \cdot 2$ & $4 \cdot 0$ & $90 \cdot 4$ \\
\hline Females $14-18$ years & 58 & $608 \cdot 0$ & $408 \cdot 5$ & $595 \cdot 8$ & $98 \cdot 3$ & $2 \cdot 9$ & $2 \cdot 7$ & $2 \cdot 6$ & $98 \cdot 3$ \\
\hline
\end{tabular}

*The RDA for $\mathrm{Ca}$ is $1300 \mathrm{mg} / \mathrm{d}$ for those aged $9-18$ years (Estimated Average Requirement $=1000 \mathrm{mg} / \mathrm{d}$ ) ${ }^{(17)}$

tThe RDA for vitamin D is $15 \mu \mathrm{g} / \mathrm{d}$ for those aged $9-18$ years (Estimated Average Requirement $=10 \mu \mathrm{g} / \mathrm{d}$ ) ${ }^{(17)}$

Table 5 Distribution of milk and alternatives, Ca and vitamin D intakes according to BMI category: schoolchildren in grades 6 to 12 , First Nations communities, northern and southern Ontario, Canada

\begin{tabular}{|c|c|c|c|c|c|c|c|c|c|c|c|c|c|}
\hline \multirow[b]{3}{*}{ Food group or nutrient } & \multicolumn{4}{|c|}{ Normal weight* } & \multicolumn{4}{|c|}{ Overweight } & \multicolumn{4}{|c|}{ Obese } & \multirow[b]{3}{*}{$P$ valuet } \\
\hline & \multirow[b]{2}{*}{$n$} & \multicolumn{3}{|c|}{ Intake } & \multirow[b]{2}{*}{$n$} & \multicolumn{3}{|c|}{ Intake } & \multirow[b]{2}{*}{$n$} & \multicolumn{3}{|c|}{ Intake } & \\
\hline & & Mean & SD & Median & & Mean & SD & Median & & Mean & SD & Median & \\
\hline $\begin{array}{l}\text { Milk \& alternatives (servings/d) } \\
\text { Ca }(\mathrm{mg} / \mathrm{d}) \\
\text { Vitamin } D(\mu \mathrm{g} / \mathrm{d})\end{array}$ & 163 & $\begin{array}{r}1.9 \\
816 \cdot 7 \\
3.5\end{array}$ & $\begin{array}{r}1 \cdot 8 \\
644 \cdot 9 \\
3 \cdot 9\end{array}$ & $\begin{array}{r}1 \cdot 5 \\
665 \cdot 6 \\
2 \cdot 7\end{array}$ & 107 & $\begin{array}{r}1 \cdot 7 \\
698 \cdot 4 \\
3 \cdot 2\end{array}$ & $\begin{array}{r}1 \cdot 7 \\
549 \cdot 7 \\
3 \cdot 3\end{array}$ & $\begin{array}{r}1 \cdot 5 \\
608 \cdot 8 \\
2 \cdot 5\end{array}$ & 66 & $\begin{array}{r}1 \cdot 6 \\
675 \cdot 8 \\
2 \cdot 6\end{array}$ & $\begin{array}{r}1 \cdot 6 \\
510 \cdot 6 \\
2 \cdot 8\end{array}$ & $\begin{array}{r}1 \cdot 4 \\
577 \cdot 3 \\
1 \cdot 8\end{array}$ & $\begin{array}{l}0.702 \\
0.206 \\
0.118\end{array}$ \\
\hline
\end{tabular}

${ }^{*}$ Overweight and obesity as defined by the International Obesity Taskforce cut-offs ${ }^{(14)}$. Overweight youth have a BMl equivalent to adults with BMI $\geq 25 \cdot 0 \mathrm{~kg} / \mathrm{m}^{2}$; obese youth have a BMl equivalent to adults with $\mathrm{BMI} \geq 30 \cdot 0 \mathrm{~kg} / \mathrm{m}^{2}$.

$+P$ value for the ANOVA based on energy-adjusted intakes (per $4184 \mathrm{~kJ}$ ); however, values in table are unadjusted.

Albany Winter 2007 data collection ( $n$ 50). In other cases participants declined to report their height or weight, leaving 336 participants in the analysis. ANOVA revealed no significant differences in intakes of any of the key dietary variables between the three BMI categories (Table 5). A significant BMI $\times$ sex interaction was found for milk and alternatives $(P=0 \cdot 041$; data not shown $)$. Among females, there appeared to be an inverse association between milk and alternatives intake and BMI category; among males, those who were overweight had the highest intake, followed by those who were normal weight and obese (data not shown). Overall, of the normal-weight participants, $21.5 \%$ had an adequate intake of milk and alternatives, compared with $14.0 \%$ of the overweight and $16.7 \%$ of the obese participants (data not shown).

\section{Community variation in intakes}

ANOVA revealed significant community differences in the intakes of milk and alternatives $(P=0 \cdot 020)$, Ca $(P=0 \cdot 019)$ and vitamin $\mathrm{D}(P=0 \cdot 018)$ for the Autumn 2004 Christian Island-Fort Albany pair; intakes were higher in Fort Albany (Table 6). Significant differences in the intakes of milk and alternatives $(P=0.002)$ and $\mathrm{Ca}(P=0.002)$ were seen for the Winter 2007 Moose Factory-Fort Albany pair; overall intakes were higher in Fort Albany. A significant community $\times$ age $\times$ sex interaction was seen for milk and alternatives $(P=0 \cdot 040)$, $\mathrm{Ca}(P=0.005)$ and vitamin $\mathrm{D}(P=0.030)$ for this pair (data not shown). While older males in Fort Albany had higher intakes of milk and alternatives $(P=0.025)$ and $\mathrm{Ca}$ $(P=0.003)$ and lower intakes of vitamin $\mathrm{D}(P=0.003)$ than those in Moose Factory, there was no difference for 
Table 6 Comparison of intakes of selected nutrients by degree of remoteness using community pairs: schoolchildren in grades 6 to 12 , First Nations communities, northern and southern Ontario, Canada

\begin{tabular}{|c|c|c|c|c|c|c|}
\hline \multirow[b]{2}{*}{ Food group or nutrient } & \multirow[b]{2}{*}{ Community } & \multirow[b]{2}{*}{$n$} & \multicolumn{3}{|c|}{ Intake } & \multirow[b]{2}{*}{$P$ value* } \\
\hline & & & Mean & SD & Median & \\
\hline \multicolumn{7}{|l|}{ Autumn 2004} \\
\hline \multirow[t]{2}{*}{ Milk and alternatives (servings/d) } & Christian Islandt & 40 & $0 \cdot 8$ & $1 \cdot 1$ & $0 \cdot 4$ & $0 \cdot 020$ \\
\hline & Fort Albany & 63 & $1 \cdot 7$ & $1 \cdot 7$ & 1.5 & \\
\hline \multirow{2}{*}{$\mathrm{Ca}(\mathrm{mg} / \mathrm{d})$} & Christian Island & 40 & $498 \cdot 9$ & $386 \cdot 4$ & $368 \cdot 7$ & 0.019 \\
\hline & Fort Albany & 63 & $842 \cdot 0$ & 573.5 & $727 \cdot 3$ & \\
\hline \multirow[t]{2}{*}{ Vitamin D $(\mu \mathrm{g} / \mathrm{d})$} & Christian Island & 40 & $2 \cdot 1$ & $2 \cdot 6$ & 1.0 & $0 \cdot 018$ \\
\hline & Fort Albany & 63 & $4 \cdot 5$ & $4 \cdot 5$ & $3 \cdot 8$ & \\
\hline \multicolumn{7}{|l|}{ Winter 2005} \\
\hline \multirow[t]{2}{*}{ Milk and alternatives (servings/d) } & Attawapiskatł & 62 & $2 \cdot 6$ & $2 \cdot 6$ & $1 \cdot 9$ & $0 \cdot 494$ \\
\hline & Peawanuck & 10 & $1 \cdot 9$ & $1 \cdot 4$ & 1.5 & \\
\hline \multirow[t]{2}{*}{$\mathrm{Ca}(\mathrm{mg} / \mathrm{d})$} & Attawapiskat & 62 & $934 \cdot 2$ & $835 \cdot 2$ & $748 \cdot 6$ & 0.382 \\
\hline & Peawanuck & 10 & $1090 \cdot 8$ & $842 \cdot \overline{6}$ & $827 \cdot 2$ & \\
\hline \multirow[t]{2}{*}{ Vitamin D $(\mu \mathrm{g} / \mathrm{d})$} & Attawapiskat & 62 & $5 \cdot 0$ & $5 \cdot 1$ & $4 \cdot 0$ & 0.722 \\
\hline & Peawanuck & 10 & $3 \cdot 6$ & $2 \cdot 7$ & $2 \cdot 6$ & \\
\hline \multicolumn{7}{|l|}{ Winter 2007} \\
\hline \multirow[t]{2}{*}{ Milk and alternatives (servings/d) } & Moose Factory§ & 82 & $1 \cdot 8$ & $1 \cdot 8$ & $1 \cdot 5$ & 0.002 \\
\hline & Fort Albany & 50 & $2 \cdot 7$ & $2 \cdot 2$ & $2 \cdot 1$ & \\
\hline \multirow[t]{2}{*}{$\mathrm{Ca}(\mathrm{mg} / \mathrm{d})$} & Moose Factory & 82 & $714 \cdot 3$ & $573 \cdot 3$ & $569 \cdot 7$ & 0.002 \\
\hline & Fort Albany & 50 & $1004 \cdot 5$ & $733 \cdot 3$ & $740 \cdot 8$ & \\
\hline \multirow{2}{*}{ Vitamin D $(\mu \mathrm{g} / \mathrm{d})$} & Moose Factory & 82 & $3 \cdot 7$ & $3 \cdot 4$ & $2 \cdot 8$ & 0.071 \\
\hline & Fort Albany & 50 & $5 \cdot 6$ & $5 \cdot 1$ & $5 \cdot 4$ & \\
\hline \multicolumn{7}{|l|}{ Spring 2009} \\
\hline \multirow[t]{2}{*}{ Milk and alternatives (servings/d) } & Fort Albany\| & 30 & $1 \cdot 8$ & $1 \cdot 1$ & $1 \cdot 7$ & 0.723 \\
\hline & Kashechewan & 43 & $2 \cdot 2$ & 1.9 & $1 \cdot 8$ & \\
\hline \multirow[t]{2}{*}{$\mathrm{Ca}(\mathrm{mg} / \mathrm{d})$} & Fort Albany & 30 & $785 \cdot 4$ & $423 \cdot 5$ & $682 \cdot 4$ & 0.522 \\
\hline & Kashechewan & 43 & $812 \cdot 9$ & $577 \cdot 5$ & $679 \cdot 4$ & \\
\hline \multirow[t]{2}{*}{ Vitamin D $(\mu \mathrm{g} / \mathrm{d})$} & Fort Albany & 30 & $2 \cdot 7$ & $2 \cdot 4$ & $2 \cdot 2$ & $0 \cdot 719$ \\
\hline & Kashechewan & 43 & $2 \cdot 4$ & $2 \cdot 4$ & $2 \cdot 0$ & \\
\hline
\end{tabular}

${ }^{*} P$ value for the ANOVA based on energy-adjusted intakes (per $4184 \mathrm{~kJ}$ ); however, values in table are unadjusted. tChristian Island is more remote than Fort Albany.

$\ddagger$ Peawanuck is more remote than Attawapiskat.

§Fort Albany is more remote than Moose Factory.

\|Kashechewan is more remote than Fort Albany.

younger males (data not shown). Among females there was no difference in intakes of milk and alternatives between communities; younger females in Fort Albany had higher intakes of $\mathrm{Ca}(P=0 \cdot 001)$ and lower intakes of vitamin D $(P=0.023)$ than those in Moose Factory, with no difference observed for older females (data not shown).

\section{Discussion}

\section{Milk and alternatives and associated nutrient intakes}

Our results are similar to those reported for other Aboriginal populations, where low intakes of milk and alternatives and their associated nutrients were documented among children and youth. For example, a 2005 literature review of the eating habits of Canadian Aboriginal populations showed diets low in $\mathrm{Ca}$ and vitamin $\mathrm{D}$, among other nutrients ${ }^{(1)}$. Findings from the current study are congruent with these findings; $86.2 \%$ of individuals had an intake of Ca below the RDA and $96 \cdot 4 \%$ had an intake of vitamin D below the RDA. Mean intakes of the group were not compared with the Estimated Average Requirement, as this represents the intake that would meet the needs of $50 \%$ of the population, therefore comparing with mean intakes would not yield valuable information. Thus, statements about possible inadequacy due to intakes lower than the RDA refer specifically to individuals and are not applied at a group level. A recent study in northern Quebec, Canada showed that approximately $80 \%$ of Aboriginal children failed to meet the recommendations of Canada's Food Guide for milk and alternatives ${ }^{(10)}$, a figure similar to what was found in the current study, where $72 \cdot 6 \%$ to $84 \cdot 7 \%$ of youth failed to meet Canada's Food Guide recommendations, depending on age and sex. While two versions of the Canadian Nutrient File (2001 or 2007) were used to analyse intakes, these reflect foods available at the time of the data collections and should not have impacted results. Other sources of Ca and vitamin D were not investigated, although any food reported within the $24 \mathrm{~h}$ recall could contribute to nutrient intakes. Other dietary sources of Ca and vitamin D are part of some traditional Aboriginal diets and include fatty fish, fish eaten with bones, bannock prepared with baking powder, nuts and beans, leafy green vegetables and seaweed $^{(19)}$. These were present within the WEB-Q but did not contribute specifically to milk and alternatives intake as defined by Canada's Food Guide. It has been reported 
that these sources tend to be consumed infrequently among Aboriginal youth in some communities ${ }^{(10)}$; frequency of intake among youth in the current study was not investigated. A recent study in Cree youth from Quebec, Canada found milk to be the top contributor to both $\mathrm{Ca}$ and vitamin D intakes $^{(10)}$. Further study into the contribution of traditional foods to $\mathrm{Ca}$ and vitamin $\mathrm{D}$ intakes would be of interest, taking into account that traditional foods consumed are community specific.

The findings of the present study are important given the health implications associated with a low intake of milk and alternatives. The First Nations Bone Health Study found an association between Aboriginal ethnicity and low bone mass in women ${ }^{(8)}$. Rural Aboriginal women had lower $\mathrm{Ca}$ and vitamin $\mathrm{D}$ intakes than urban white or Aboriginal women, with $32 \%$ of rural Aboriginal women being deficient in vitamin D (serum 25-hydroxycholecalciferol $<37 \cdot 5 \mathrm{mmol} / 1$ ) ${ }^{(7)}$. Also, rickets (vitamin D deficiency) still occurs in Canada, with the highest rates seen in the north, where sun exposure is low ${ }^{(20)}$ and/or skin exposure minimal due to the presence of biting insects (long sleeves and trousers are worn). Thus, the low intake of milk and alternatives among youth in the present population is concerning. Without adequate intake of this food group, these youth may be at risk for osteoporosis and other problems later in life. Further, the link between the intake of milk, dietary $\mathrm{Ca}$ and a healthy body weight ${ }^{(4,21)}$ suggests that suboptimal intake of milk and alternatives in this population may be contributing to the elevated rates of overweight and obesity.

The current findings suggest a need to improve dietary intakes of milk and alternatives, $\mathrm{Ca}$ and vitamin $\mathrm{D}$ in this population. Taylor et al. suggested in 2007 the need for health promotion and education programmes to improve dietary practices ${ }^{(22)}$. School nutrition programmes are a viable approach for behaviour change in FN youth, where adequate resources exist. Comprehensive programmes that address multiple influences on a child's dietary knowledge, attitudes and intentions would be ideal, and may help children and youth to overcome barriers to healthy eating. The results presented here suggest the need for such initiatives.

Unfortunately, in many FN communities, adequate resources for school nutrition programmes are not available. Barriers to successful programme implementation can include the following: inadequate facilities and storage; poor food availability, variety and quality and high prices; lack of availability of volunteers; and high operating costs $^{(23)}$. As well, a large proportion of the North American Aboriginal population may be lactose intolerant ${ }^{(24)}$, which could be a barrier to achieving adequate intake. However, in a sample of students in Fort Albany, Kashechewan and Attawapiskat FN, there were no children who reported having a milk allergy/intolerance or feeling sick when they drank milk (M Gates, unpublished results). Milk alternatives are available in most communities; fortified soya beverage is usually available, but is expensive (as is milk). Food price data from Fort Albany in February 2010 revealed that a 2-litre carton of $2 \%$ milk cost \$CDN 7.95 v. \$CDN 8.29 for 2 litres of fortified soya beverage, a difference of \$CDN $0 \cdot 34$. Yoghurt and cheese are also usually available; these products can sometimes be tolerated by those with lactose intolerance.

\section{Association between milk and alternatives and BMI}

There was a BMI $\times$ sex interaction for the intake of milk and alternatives in our sample. For females, there appeared to be an inverse association between milk and alternatives intake and BMI category, as expected. However, among males the association was not as expected; overweight males had the highest intake, followed by those who were normal weight and then those who were obese. The association observed in females parallels the inverse association between milk consumption and the risk of being overweight seen in a study of schoolchildren in southern Italy ${ }^{(21)}$. Mean intakes of $\mathrm{Ca}$ and vitamin $\mathrm{D}$ were not associated with BMI category in our sample. This is in contrast to the inverse association between dietary $\mathrm{Ca}$ intake and body weight that has been seen in some epidemiological studies ${ }^{(4,5)}$. However, it is possible that the association between BMI and $\mathrm{Ca}$ intake may not hold true for FN youth, such as our study population. In any case, the intakes of milk and alternatives and their associated nutrients were low for all age and sex categories under study; while the prevalence of overweight and obesity was high. Since an overall trend was seen with a higher proportion of normal-weight individuals consuming adequate milk and alternatives as compared with overweight or obese individuals, it is possible that the sample size was inadequate to detect such an association. In addition, the current study did not look at sweetened beverage intake, but it is known that high intakes of sugar-sweetened beverages exist in other Aboriginal communities across Canada ${ }^{(25,26)}$. Sweetened beverage intake has been identified as an independent predictor of weight gain and obesity in children and youth ${ }^{(27)}$. Further analysis of sweetened beverage intake in relation to milk and alternatives and BMI would be of interest in this population to help clarify the association between these variables.

\section{Community variation in intakes}

It was thought that more northerly, remote communities would have lower intakes of milk and alternatives and their associated nutrients than more southerly, less-remote communities due to the increasing cost of food (especially with air freight) as communities become more remote. Using pairs of communities sampled in the same season and year, a comparison by community showed variation in milk and alternatives and associated nutrient intakes between Christian Island and Fort Albany in Autumn 2004, 
and between Moose Factory and Fort Albany in Winter 2007. These results were unexpected, as Fort Albany is more northerly and remote (being a fly-in community) than the comparison communities of Christian Island and Moose Factory. However, in both cases youth in Fort Albany had greater intakes milk and alternatives, Ca and vitamin D (Christian Island comparison only) than the comparison community. However, it is suspected that the snack programme in place at the school in Fort Albany, which has been running successfully for over 20 years, may be responsible for the higher intakes of milk and alternatives, $\mathrm{Ca}$ and vitamin $\mathrm{D}$ seen in that community. The fact that youth in this community are consistently supplied with milk and alternative products on a daily basis may be a factor. It would be of interest to compare community variation in intakes during the summer months when youth are not in school and cannot rely on the snack programme. This may indicate the positive impacts that school-based nutrition programmes can have on the diets of FN youth, and may provide evidence for the benefits of such programmes in areas where access to healthy foods may be otherwise limited. Further investigation will be needed to clarify the association between remoteness and milk and alternatives intake in Ontario FN communities.

\section{Limitations}

Because of the great diversity seen in FN populations, the results presented herein may not be representative of other FN populations, but remain particularly useful for the Ontario FN communities in this study. In some cases, small sample sizes may have limited our ability to detect differences in intakes, but this was beyond our control. To optimize participation rates, all children and youth attending school on the day of data collection were included; efforts were made to include those who were not present on a particular day, for example by scheduling data collections over two or more days.

The $24 \mathrm{~h}$ recall is a meaningful measure of the average intakes of groups ${ }^{(28)}$, and was chosen with its feasibility for the study population in mind. The $24 \mathrm{~h}$ recall has certain limitations including its reliance on memory, difficulty of portion size estimation and under-reporting ${ }^{(28-30)}$. Social desirability bias is a concern due to the presence of research assistants in the room and the close proximity of the computers. As with all self-reports of diet, recall bias can also be a problem, where participants will selectively recall certain foods. Further, systematic under-reporting remains a problem even with web-based tools ${ }^{(31)}$. Finally, one $24 \mathrm{~h}$ recall does not measure usual intake and does not represent the day-to-day variability in diets that exists ${ }^{(28)}$. Logistical constraints, the cost of northern research and respondent burden make multiple recalls unfeasible. However, the $24 \mathrm{~h}$ recall remains a useful, low-burden tool for population-level assessments.

Self-reported height and weight were used in the calculation of BMI. It has been shown that self-reported heights and weights are well correlated with actual height and weight, but individuals tend to over-report their height and under-report their weight ${ }^{(32)}$. Underestimation of BMI may have affected results for prevalence of overweight and obesity. This limitation may also impact the assessment of the association between milk intake and BMI (e.g. those concerned with their body weight may simultaneously drink more milk and under-report their weight).

\section{Conclusions}

In summary, the present study has confirmed that northern and southern Ontario on-reserve FN youth are similar to other Canadian Aboriginal youth, with low intakes of milk and alternatives, $\mathrm{Ca}$ and vitamin $\mathrm{D}$, and a high prevalence of overweight and obesity that exceeds that of the general population. The current data do not support the inverse association between $\mathrm{Ca}$ and BMI. The association between milk and alternatives intake and BMI was not as expected among males, but higher intake appeared to be associated with normal weight in females. A trend towards a greater proportion of overweight and obese individuals having inadequate milk and alternatives intake as compared with normal-weight individuals was seen. Further study would be needed to clarify this association. The diets and BMI of FN youth suggest the need for community-based interventions to improve the intake of milk and alternatives within this population. The current community comparison, testing the association between milk and alternatives intake and remoteness, has suggested that a snack programme in Fort Albany may have had a positive impact upon youth in that community.

\section{Acknowledgements}

This research was funded by the Canadian Institutes of Health Research (CIHR; grant \#178424); Canada's Research-Based Pharmaceutical Companies Health Research Foundation; the Heart and Stroke Foundation of Ontario; Health Canada's First Nations and Inuit Health Branch; the Danone Institute of Canada; the Ontario Ministry of Research and Innovation; and the CIHR Training Grant in Population Health Intervention for Chronic Disease Prevention: A Pan-Canadian Program (grant \#53893). The authors declare no conflicts of interest. M.G. participated in the design and coordination of the study, collected data, performed statistical analyses and drafted the manuscript. R.M.H. participated in the design and coordination of the study, data interpretation and helped to draft the manuscript. A.G. participated in the design and coordination of the study, collected data and helped draft the manuscript. I.D.M. advised on and helped perform statistical analyses and data interpretation. L.J.S.T. participated in the design and coordination of the study, data interpretation and 
helped to draft the manuscript. All authors read and approved the final manuscript. The authors would like to thank individuals in the First Nations communities who participated in this research. They also extend special thanks to all of the community-based research assistants and advisory groups.

\section{References}

1. Willows ND (2005) Determinants of healthy eating in Aboriginal peoples in Canada, the current state of knowledge and research gaps. Can J Public Health 96, Suppl. 3, S32-S36.

2. Story M, Stevens J, Himes J et al. (2003) Obesity in American-Indian children: prevalence, consequences, and prevention. Prev Med 37, Suppl. 6, S3-S12.

3. Swinburn BA, Caterson I, Seidell JA et al. (2004) Diet, nutrition, and the prevention of excess weight gain and obesity. Public Health Nutr 7, 123-146.

4. Heaney RP (2003) Normalizing calcium intake: projected population effects for body weight. J Nutr 133, Suppl. 1, S268-S270.

5. Teergarden D (2003) Calcium intake and reduction in fat mass. J Nutr 133, Suppl. 1, S249-S251.

6. Health Canada (2007) Eating Well with Canada's Food Guide for First Nations, Inuit, and Métis. http://www.hc-sc.gc.ca/ fn-an/pubs/fnim-pnim/index-eng.php (accessed June 2012).

7. Weiler HA, Leslie WD, Krahn J et al. (2007) Canadian Aboriginal women have a higher prevalence of vitamin D deficiency than non-Aboriginal women despite similar vitamin D intakes. J Nutr 137, 461-465.

8. Leslie WD, Metge CJ, Weiler HA et al. (2006) Bone density and bone area in Canadian Aboriginal women: the First Nations Bone Health Study. Osteoporos Int 17, 1755-1762.

9. Leslie WD, Derksen S, Metge C et al. (2004) Fracture risk among First Nations people: a retrospective matched cohort study. CMAJ 171, 869-873.

10. Downs SM, Arnold A, Marshall D et al. (2009) Associations among the food environment, diet quality and weight status in Cree children in Québec. Public Health Nutr 12, 1504-1511.

11. Gates A, Hanning RM, Gates M et al. (2012) Vegetable and fruit intakes of on-reserve First Nations schoolchildren fall short of national averages and current recommendations. Int J Environ Res Public Health 9, 1379-1397.

12. Hanning RM, Royall D, Toews J et al. (2009) Web-based food behaviour questionnaire: validation with grades six to eight students. Can J Diet Pract Res 70, 172-178.

13. Gates M (2009) Electronic Dietary Assessment, Practicebased Evidence in Nutrition (PEN) Pathway. http://www. pennutrition.com (accessed June 2012).

14. Cole TJ, Bellizi MC, Flegal KM et al. (2000) Establishing a standard definition for child overweight and obesity worldwide: international survey. BMJ 320, 1240-1243.

15. Health Canada (2010) Canadian Nutrient File. http://www. hc-sc.gc.ca/fn-an/nutrition/fiche-nutri-data/index-eng.php (accessed June 2012).

16. Garriguet D (2007) Canadians' eating habits. Health Rep 18, $17-32$.
17. Institute of Medicine (2011) Dietary Reference Intakes for Calcium and Vitamin D [AC Ross, CL Taylor, AL Yaktine et al., editors]. Washington, DC: The National Academies Press.

18. Willett WC, Howe GR \& Kushi LH (1997) Adjustment for total energy intake in epidemiologic studies. Am J Clin Nutr 65, Suppl. 1, S1220-S1228.

19. Willows ND (2011) Improving the nutritional status of Aboriginal people in Canada. The Diabetes Communicator. http://www.diabetes.ca/documents/for-professionals/DCSpring_2011-N.Willows_.pdf (accessed June 2012).

20. Ward LM, Gaboury I, Ladhani MD et al. (2007) Vitamin Ddeficiency rickets among children in Canada. CMAJ 177, 161-166.

21. Barba G, Troiano E, Russo P et al. (2005) Inverse association between body mass and frequency of milk consumption in children. Br J Nutr 93, 15-19.

22. Taylor JP, Timmons V, Larsen R et al. (2007) Nutritional concerns in Aboriginal children are similar to those in non-Aboriginal children in Prince Edward Island, Canada. J Am Diet Assoc 107, 951-955.

23. Hanning RM, Skinner K, Gates M et al. (2001) School nutrition programs in remote First Nation communities of the Western James Bay region: impact, challenges, and opportunities. In Population Health Intervention Research Casebook, pp. 45-48. Ottawa: Canadian Institutes of Health Research - Institute of Population and Public Health, Canadian Institute for Health Information - Canadian Population Health Initiative; available at http://www. cihr-irsc.gc.ca/e/43472.html

24. Born P (2007) Carbohydrate malabsorption in patients with non-specific abdominal complaints. World J Gastroenterol 13, 5687-5691.

25. Garriguet D (2008) Obesity and the eating habits of the Aboriginal population. Health Rep 19, 1-15.

26. Willows ND (2005) Overweight in Aboriginal children: prevalence, implications and solutions. J Aboriginal Health 2, 76-85.

27. Malik VS, Schulze MB \& Hu FB (2006) Intake of sugarsweetened beverages and weight gain: a systematic review. Am J Clin Nutr 84, 274-288.

28. Thompson FE \& Subar AF (2001) Dietary assessment methodology. In Nutrition in the Prevention and Treatment of Disease, 2nd ed., pp. 1-39 [AM Coulston, CL Rock and ER Monsen, editors]. San Diego, CA: Academic Press.

29. Johansson G, Wikman A, Ahren A-M et al. (2001) Underreporting of energy intake in repeated 24-hour recalls related to gender, age, weight status, day of interview, educational level, reported food intake, smoking habits and area of living. Public Health Nutr 4, 919-927.

30. Moshfegh AJ, Rhodes DG, Baer DJ et al. (2008) The US Department of Agriculture Automated Multiple-Pass Method reduces bias in the collection of energy intakes. Am J Clin Nutr 88, 324-332.

31. Vance VA, Woodruff SJ, McCargar CJ et al. (2009) Selfreported dietary energy intake of normal weight, overweight and obese adolescents. Public Health Nutr 12, 222-227.

32. Spencer EA, Appleby PN, Davey GK et al. (2002) Validity of self-reported height and weight in 4808 EPIC-Oxford participants. Public Health Nutr 5, 561-565. 